\section{CPS-279 THE EFFECT OF CONTINUATION OF HOME MEDICATION BY HOSPITALISED PATIENTS ON MEDICATION WASTE AND PATIENT SATISFACTION, A MULTICENTRE, QUASI-EXPERIMENTAL STUDY WITH A PRE-POST DESIGN}

\begin{abstract}
1,2L Van Herpen-Meeuwissen*, ${ }^{3} \mathrm{~B}$ Maat, ${ }^{1,4} \mathrm{~B}$ Van den Bemt, ${ }^{5} \mathrm{H}$ Van Onzenoort. ${ }^{1}$ Radboud University Medical Centre, Pharmacy, Nijmegen, The Netherlands; ${ }^{2}$ Radboud Institute For Health Sciences, Pharmacy, Nijmegen, The Netherlands; ${ }^{3}$ Elisabeth-Tweesteden Hospital, Pharmacy, Tilburg, The Netherlands; ${ }^{4}$ Sint Maartenskliniek, Pharmacy, Nijmegen, The Netherlands; ${ }^{5}$ Amphia Hospital, Pharmacy, Breda, The Netherlands
\end{abstract}

\subsection{6/ejhpharm-2019-eahpconf.428}

Background The majority of all hospitalised patients use medication at home. On admission, patient's medication is often ordered or changed to the hospital's formulary. Therefore, the use of home medication during hospitalisation (HMDH) may prevent unnecessary medication waste, because currently ordered medication is disposed of at discharge. Furthermore, these medication changes have the potential to cause harm. In addition, they oppose the possibility for patients to participate in their pharmaceutical treatment. Therefore, the implementation of $\mathrm{HMDH}$ may increase patient satisfaction.

Purpose The aim of this study was to investigate the effect of $\mathrm{HMDH}$ on medication waste and patient satisfaction.

Material and methods This multicentre quasi-experimental study was conducted at seven different nursing wards, including both surgical and non-surgical wards. During pre- and post-implementation of $\mathrm{HMDH}$, data were collected for 2 months at a time. Medication waste was measured by identifying all disposed medication for at least 1 month during both periods. The following data were collected: price per unit on November 2017, unique medication identification number and the amount of medication disposed of. Patient satisfaction was measured using a questionnaire about patients' perceptions and beliefs. The results of the questionnaire were statistically tested by performing a $t$-test.

Results The total value of disposed medication was $€ 14954$ (SD $€ 2,887$ ) and $€ 10728$ (SD $€ 1,728$ ) per month, during pre- and post-implementation of $\mathrm{HMDH}$, respectively. $\mathrm{HMDH}$ led to a reduction of $28.3 \%$ in medication waste costs. Extrapolation of these data to the national level may theoretically lead to $€ 15$ million savings annually in medication costs. In total, 912 patients completed the questionnaire. Pre-implementation, 69\% $(n=357)$ of all patients were positive about $\mathrm{HMDH}$. When $\mathrm{HMDH}$ was implemented, this number significantly increased to $83 \%(\mathrm{n}=328 ; \mathrm{p}<0.05)$.

\begin{tabular}{lllll}
\multicolumn{6}{l}{ Abstract 4CPS-279 Table 1} \\
\hline WARD & MEDICATION WASTE & \multicolumn{3}{l}{ COST } \\
& & \multicolumn{5}{l}{ DIFFERENCE } \\
\hline & Pre-implementation of & Post-implementation of & Absolute & Relative \\
& HMDH (€) & HMDH (€) & $(€)$ & $(\%)$ \\
A & 243 & 292 & 49 & 20.0 \\
B & 4296 & 2718 & $-1,578$ & -36.7 \\
C & 1290 & 1263 & -27 & -2.1 \\
D & 7571 & 4902 & $-2,670$ & -35.3 \\
E & 440 & 923 & 482 & 109.6 \\
F & 1113 & 631 & -482 & -43.3 \\
Total & 14954 & 10728 & $-4,226$ & -28.3 \\
\hline
\end{tabular}

Conclusion The results of this study show that implementation of HMDH decreases costs associated with medication waste. In addition, the introduction of $\mathrm{HMDH}$ increases patient satisfaction.

\section{REFERENCES AND/OR ACKNOWLEDGEMENTS}

No conflict of interest.

\section{CPS-280 DOES PLATELET-RICH PLASMA COMPOSITION MATTER IN HIP OSTEOARTHRITIS?}

${ }^{1} \mathrm{MDM}$ Villanova Lopez ${ }^{*},{ }^{2} \mathrm{M}$ Nunez-Nunez, ${ }^{3} \mathrm{M}$ Murillo-Izquierdo, ${ }^{4} \mathrm{~J}$ Donaire, ${ }^{5} \mathrm{R}$ Alvarez Sanchez, ${ }^{3} \mathrm{M}$ Camean-Fernandez, ${ }^{3} \mathrm{~S}$ Sandoval. ${ }^{1}$ Hospital Hospiten, Traumatology, Malaga, Spain; ${ }^{2}$ Hospital San Cecilio- Granada, Pharmacy, Granada, Spain; ${ }^{3}$ Hospital Macarena, Pharmacy, Sevilla, Spain; ${ }^{4}$ Hospital La Línea, Traumatology, Cadiz, Spain; ${ }^{5}$ Hospital San Cecilio, Pharmacy, Granada, Spain

\subsection{6/ejhpharm-2019-eahpconf.429}

Background Analgesic and antiinflamatory (AA) activity of autologous platelet-rich plasma (PRP) yields in its concentration on blood-cell counts and certain growth factors, although, clinical correlation is poorly described.

Purpose We sought to analyse clinical outcomes and its growth factors and blood cell concentration of PRP.

Material and methods A cohort study of adult patients with hip osteoarthritis (OA) who had failed previous conservative treatment and received a single intra-articular injection of autologous PRP) for pain management.

Follow-up period: 1 year with clinical evaluations at baseline (day of PRP administration) and at 1, 4, 24 and 48 weeks. The primary outcome measure was a change in the Western Ontario and McMaster Universities Osteoarthritis Index (WOMAC) and secondary outcomes: Harris Hip Score (HHS), Visual Analogue Scale (VAS), responders' rate (OARSI Criteria), analgesic treatment, cell counts and the contents of vascular endothelial growth factor (VEGF), platelet-derived growth factor $\mathrm{AB}$ (PDGF-AB), transforming growth factor beta 1 (TGF-b1), interlekin beta 1 (IL-B1) and insulin growth factor (IGF) concentration of growth factors in PRP. Uni- and multivariate analyses were performed using SPSS v.18.

Results Thirty-eight patients were included. A better response to treatment was observed in those patients with a baseline grade 1-2 of Kellgren Larwrence (11.51 OR, 95\% CI: 2.34 to $50.65, \mathrm{p}<0.03)$. Significant high correlation was found between white cells' concentration-VAS score $(r=0.748$, $\mathrm{p}<0.013)$ and white cells' concentration-WOMAC stiffness $(\mathrm{r}=0.748, \mathrm{p}<0.013)$. Moreover, moderate correlation was

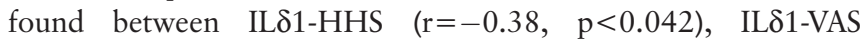

